Wilfrid Laurier University

Scholars Commons @ Laurier

Lyle S. Hallman Social Work Faculty

Publications

Lyle S. Hallman Faculty of Social Work

Winter 2007

\title{
Practising Interprofessional Teamwork From the First Day of Class: A Model for an Interprofessional Palliative Care Course
}

\author{
Susan Cadell \\ Wilfrid Laurier University, scadell@wlu.ca \\ Harvey Bosma \\ University of British Columbia \\ Meghan Fletcher Johnston \\ University of British Columbia \\ Pat Porterfield \\ Vancouver Coastal Health \\ Leah Cline \\ Canuck Place Children's Hospice
}

See next page for additional authors

Follow this and additional works at: https://scholars.wlu.ca/scwk_faculty

\section{Recommended Citation}

Cadell, Susan; Bosma, Harvey; Fletcher Johnston, Meghan; Porterfield, Pat; Cline, Leah; Fraser, Jacky; and Boston, Pat, "Practising Interprofessional Teamwork From the First Day of Class: A Model for an Interprofessional Palliative Care Course" (2007). Lyle S. Hallman Social Work Faculty Publications. 13. https://scholars.wlu.ca/scwk_faculty/13

This Article is brought to you for free and open access by the Lyle S. Hallman Faculty of Social Work at Scholars Commons @ Laurier. It has been accepted for inclusion in Lyle S. Hallman Social Work Faculty Publications by an authorized administrator of Scholars Commons @ Laurier. For more information, please contact scholarscommons@wlu.ca. 


\section{Authors}

Susan Cadell, Harvey Bosma, Meghan Fletcher Johnston, Pat Porterfield, Leah Cline, Jacky Fraser, and Pat Boston 
Practising Interprofessional Teamwork From the First Day of Class: a Model for an Interprofessional Palliative Care Course

\begin{abstract}
SUSAN CADELL, Manulife Centre for Healthy Living, Lyle S. Hallman Faculty of Social Work, Wilfrid Laurier University, Kitchener, Ontario, HARVEY BOSMA and MEAGHEN JOHNSTON, School of Social Work, University of British Columbia, Vancouver, British Columbia, PAT PORTERFIELD, Vancouver Coastal Health, Vancouver, British Columbia, LEAH CLINE, Canuck Place Children's Hospice, Vancouver, British Columbia, JACK DA SILVA, St. Paul's Hospital, Vancouver, British Columbia, JACKY FRASER, Providence Health Care, Vancouver, British Columbia, PAT BOSTON, Division of Palliative Care, University of British Columbia, Department of Family Practice, Vancouver, British Columbia, Canada
\end{abstract}

\section{INTRODUCTION}

Providing care to the dying requires an interprofessional team to attend to complex needs that extend beyond the physical care of the patient. Social, psychological, emotional, and spiritual needs are equally significant care provisions for patients and their families in palliative settings. Therefore, by necessity (1-3) and by mutual assent (4), palliative care is delivered by an interprofessional team of health professionals and not by one profession alone. This article presents a model of education by describing an interprofessional palliative care course that brings together students from various health professions to provide an opportunity for learning and practice on a palliative care team.

The model of collaborative interdisciplinary learning reflects the practice of this distinct area of health care. The core course curriculum is based on the assumption that offering an effective continuum of palliative care services for patients and families requires the teamwork of health professionals from various disciplines. This includes the collaboration of doctors, nurses, social workers, spiritual care, pharmacists, and rehabilitation workers, among others. Emphasis is placed on teamwork as a necessity, rather than as an option in the palliative care setting; and conversely, a lack of interprofessional collaboration can be disadvantageous to the patient (2). Currently, there is little education available to prepare professionals for interprofessional practice (5). Consequently, it is imperative that educational programs begin to offer curricula aimed at developing both the knowledge of interprofessional practice and the skill of teamwork.
Accordingly, educational initiatives to train health professionals on interprofessional practice are needed to provide quality palliative care in the future. Wee et al. (3) posit that palliative care is a particularly fitting context for interprofessional education because "in the face of multidimensional suffering, complex problems and rapidly changing situations, effective and generous teamworking is essential" $(3, \mathrm{p} .490)$. However, it has only been in recent years that interprofessional education is regarded as an essential component of education in the health care disciplines (5). Furthermore, several recent studies have argued that early socialization to interprofessional teamwork is significant to health professionals' subsequent abilities to effectively teamwork in palliative care $(3,5,6)$.

In 2005, Health Canada documented the necessity for interprofessional education in the health system:

Changing the way we educate health providers is key to achieving system change and to ensuring that health providers have the necessary knowledge and training to work effectively in interprofessional teams within the evolving health care system $(7, \mathrm{p} .2)$

Health Canada also recommends that training in interprofessional care take place at all levels of education including undergraduate, graduate, and continuing education for professionals already working in health care. Current practice in palliative care confirms that interprofessional skill building is necessary. The findings of a study conducted by Sellick et al. (8), in which palliative care professionals were surveyed and interviewed palliative professionals, corroborate the Health Canada advisement. 
Despite these recommendations and the realities of the challenging nature of the profession, very little education is targeted at training palliative care professionals specifically (9). Current palliative care education initiatives focus on continuing education $(10,11)$. For example, although there are few formal training programs for palliative care nurses in Canada, currently these programs do not exist for other professions who work in palliative care. While some interprofessional programs exist in the US, for example the Geriatric Interdisciplinary Team Training Program (12), none are known to represent palliative care across the lifespan, including pediatric.

The literature on interprofessional training in palliative care settings highlights educational needs such as communication skills, trust building, self-awareness, and role understanding amongst the various disciplines on a health care team $(3,6,5)$. Workshop and seminar formats are widely used in conducting interprofessional training for professionals already working in the palliative care setting (13). In addition, experiential learning (i.e., patient and family interviewing) in palliative education has been successful in several evaluative studies in recent years (13-15). The effects of interprofessional training appear to increase and improve health professionals' skills in delivering quality health care as a team to patients and their families. As described by clinicians in a pediatric hospice, "The children have taught us the essential importance of our interdisciplinary staff team-in which our ability to be flexible and vulnerable with one another as well as with the children and their families becomes the entry point into appropriate caring relationships" (16).

\section{HISTORICAL OVERVIEW AND COURSE DEVELOPMENT}

The interprofessional palliative care course at University of British Columbia (UBC) is offered under the auspices of the College of Health Disciplines in cooperation with the Division of Palliative Care in the Faculty of Medicine. The College of Health Disciplines is an umbrella organization for all the health and human profession schools at UBC; it offers interprofessional health and human service courses. While the terms "multidisciplinary" and "interprofessional" are often misused and their meanings are various (17), the term "interprofessional" is used deliberately here. Gilbert (18) describes interprofessional collaboration as a "process through which parties who see different aspects of a problem can constructively explore their differences and search for solutions that go well beyond their own professional vision of what is possible." This embodies the values of the College of Health Disciplines and its courses.

The planning for the course was begun in 2001 and it was delivered for the first time in 2003. The structure of the planning committee included palliative care clinicians and scholars. The professions of those on the planning committee spanned medicine, nursing, social work, pharmacy, rehabilitation therapy, and spiritual care, and represented both adult and pediatric palliative care. The course was designed and approved by the UBC senate to include four professions: medicine, nursing, social work, and pharmacy. One faculty member from each of the professions was chosen in order to facilitate the passing of the course through the approval process of each department. These faculty members then formed the teaching core faculty for the first year of course delivery.

During the course planning, much consultation was done with various members of the interprofessional HIV/AIDS course $(19,20)$, also offered by the College of Health Disciplines at UBC. That course had extensive experience with and worked from a model of interprofessional education (20), from which the palliative care faculty benefited enormously. In addition, research into the delivery of palliative care education was undertaken. Interviews with various professionals about their own education also informed the development of the course.

\section{FORMAT OF THE COURSE}

The course, Interprofessional Health and $\mathrm{Hu}$ man Services 405: Palliative Care, is a six-credit course (equivalent to two terms) delivered in an intensive format during four weeks in the spring session. It is offered generally in the month of June in order to allow second-year medical students to join in between examinations and a placement outside the city. The course occurs four days a week; students attend class for two full days each week and are in various clinical experiences for the other two days. It has been designed for senior undergraduate students, as the mandate of the College is to provide education for this segment of the university population. The course is offered in a downtown location near a teaching hospital in order to make it most easily accessible geographically.

The course enrolment has been capped at 16 to 20 students per year: four teams of one student from each discipline of pharmacy, nursing, social work, and medicine. The cap is in place because there have been concerns about the 
course's ability to have more than four clinical sites and about the stress on the sites if the teams are bigger than four or five students. The overall goal of the course is to provide senior undergraduate health sciences students with attitudes, knowledge, skills, and abilities that enable them to begin practice in palliative care or to pursue a specialization in the field.

\section{OVERVIEW AND TEACHING STRATEGIES}

The Wyness et al. (20) model of interprofessional education includes partnership, collaborative process, and course design. Each of these components has been carefully attended to within the planning, organization, and implementation of the course. The partnerships for the palliative care course are varied and numerous. Each of the faculty members teach in partnership with their home institutions, be it a hospital or a university. In addition, the success of the course requires the involvement and commitment of all the professionals in the clinical sites who welcome and mentor the students. The development and nurturing of partnerships within the faculty, their institutions, and the professionals currently practising in the field contribute to the successful delivery and subsequently provide a good model of interprofessional practice.

The collaborative process, as articulated by Wyness et al. (20), includes assessing, building, managing, and evaluating. The assessment of the need for a palliative care course occurred through all the activities of the planning committee as outlined above. The building phase included much teambuilding on the part of the faculty members as they began to work together and committed to numerous meetings in order to get the course underway. A small but significant amount of time at each meeting was spent getting to know one another in order to build working relationships and trust. The managing of the course happened and happens in the delivery of it each and every year. The course could not happen without the administrative support of both the College of Health Disciplines and the Division of Palliative Care. The evaluation of the course occurs at the end of the four weeks.

The final component in the educational model proposed by Wyness et al. (20) is course design. This includes both interprofessional learning as well as discipline-specific learning. The course outline for the palliative care course enumerates a total of 19 objectives, which are divided into interprofessional and palliative-care-specific. The separation of the two sets of objectives reflects the philosophy of the course, with specific expectations of learning related to palliative care as well as purposeful attention to interprofessional knowledge and skill development.

The 12 palliative-care-specific objectives (Appendix 1) address the central importance of the right of the patient to have control, the centrality of the family as the unit of care, beliefs and attitudes about death and dying, communication skills, and common symptoms. It is expected that students will demonstrate their knowledge of ethical and legal issues, and of grief and loss. There are seven interprofessional objectives (Appendix 1) that cover such issues as the respect for the unique contributions of each profession, the ability to understand practice environments and their influence on teams, as well as a requirement to demonstrate principles of effective teamwork.

The two instructional days in the course begin at 9 a.m. and continue until 4:30 p.m. The class days are divided into at least four segments, some as many as six, and integrate teachings by faculty members and palliative care clinicians. The teachers of various sessions are chosen for their representation of the variety of professions in palliative care. Some faculty members present seminars. In other cases, several professionals will present together. For instance, one segment is a panel on the concept of total pain. The format of the segment is a role play by the professionals of a team meeting concerning a patient. Generally, all four core professions (medicine, nursing, social work, and pharmacy) are represented, along with spiritual care and rehabilitation. Each professional presents their own assessment of the pain of the patient and family, and their own approach to possible intervention(s).

The course includes numerous other teaching strategies. The students are assigned to interprofessional teams on the first day and much of their time, including clinical days and one of the assignments, is spent in these teams. This allows them to experience working as a team and to learn at close range the other professions.

Case-based learning is also undertaken. A case is developed over the four weeks and one session in each week is devoted to working on the case. Working in their interprofessional teams, students are asked first to reflect on what each profession prioritizes in their case presentation; they then work together to establish priorities for the team. In subsequent weeks, they are asked to work in their own discipline group, to research a specific aspect of the case, and to report back to the class what they have discovered. In addition, guest faculty are also given details of the case and encouraged to use the same case to inform their examples. 
This has led to some interesting and sometimes unexpected developments in the case over the period of learning. For instance, the case used in the classroom involves a dying mother of young children. She is presented as being in a relationship with another woman. Over the years, through the original intervention of one of the guest faculty, the case has evolved to include a biological father who reappears in the children's lives to claim custody. This layer of additional detail has provided depth and added challenge to discussion in the classroom.

\section{CLINICAL SETTINGS}

The students in their interprofessional teams spend two days of the four weeks in clinical settings. The first four visits are spent in one site in a palliative care setting. In the first year of the course, we had the teams of students rotate around the four clinical sites for the first four clinical days. This was designed to allow them to have an overview of the system in the area and the ways in which palliative care models can differ while still providing excellent care. However, this experience proved too chaotic for both the clinical facilitators and the students. In the subsequent years, each interprofessional team of students has spent the first four visits in one clinical setting. This has allowed better skills building by team members and some relationships to form with the clinical preceptors.

Additional clinical days are spent touring a funeral home, a hospice for adults, and a pediatric hospice. Vancouver is fortunate to be the site of Canuck Place, a children's hospice-the first and, until recently, only one in North America. In each of the years, teams have toured the hospice after spending time in adult palliative care. In the third year, one of the teams was placed for the first four visits in the children's hospice. This team was then sent to one of the local adult units while the other teams were visiting the pediatric site.

One of the most successful clinical experiences has been the incorporation of the stories of caregivers told to someone who has experienced palliative care. This learning exercise is based on educational practice from the UK $(21,13)$ and takes place on one of the clinical days later in the month. Two caregivers are invited in and two teams of students go with each. The caregivers are asked to tell their story for about 20 minutes and then entertain questions for the remainder of the hour. Afterward, the groups of students are brought together for a debriefing. Students report learning a great deal from the experience of listening to someone's story of direct palliative care and bereavement. Over the years, the caregivers have variously been a mother, a husband, a woman whose mother died of cancer, and a man living with HIV who cared for his partner who died of AIDS-related illness.

\section{ASSIGNMENTS}

One of the assignments in the course is considered, in part, to be a clinical experience. The students are asked to submit short weekly journal entries in response to specific questions posed throughout the weeks or to reflect on their own reactions. The students are given feedback before handing in the subsequent week's journal. They are graded on their ability to critically reflect, which can and should deepen over the four weeks. They are asked to consider how their thoughts and emotions affect their practice of palliative care specific to their own discipline. This assignment is worth $20 \%$ of the overall grade.

The students are also asked to do a presentation in class; it is undertaken and delivered in a group format in their interprofessional teams. They are asked to consider one of a number of ethical issues in palliative care, such as intravenous hydration at the end of life or terminal sedation. Collaboration and negotiation of ethical issues between team members of various disciplines can be a challenge (22). The teams are asked to invent and present a case built around the ethical issue and to address the ethics of the situation from each of their disciplines' point of view, as well as demonstrate their own work together as a team. They are asked to consider how they address conflict and are also graded on creativity. This assignment is worth $40 \%$ of the final grade.

Finally, students hand in an essay at the end of the course. They are asked to watch one of four movies and to consider how the film does or does not address the concepts of palliative care, the dying process, and interprofessional teamwork. The students are asked to incorporate relevant literature from the course and/or their own reading, and clinical experiences. They are graded on their ability to analyze critically, and to develop the paper logically and coherently. This is worth the final $40 \%$ of their grade.

\section{STUDENT FEEDBACK}

The measurement of effectiveness in palliative education is difficult (23). As this course is designed as an undergraduate introduction to a specialty, measurement of effectiveness would be particularly difficult in that it would require following students over years to evaluate their 
entry and effectiveness in the profession. In the timeframe of the course, however, students consistently rate the course highly on a quantitative evaluation common to all College of Health Discipline courses which addresses the interprofessional learning. For instance, in answer to question "Compared to the beginning of the course, do you have better skills of joint planning and decision making with other health care professionals?", the ratings have always been 3.5 and higher, with $3=$ somewhat and $4=$ very much on a 4-point scale. All five items pertaining to interprofessional knowledge and skills have consistently rated between 3 and 4 over the years of the course.

The course is re-evaluated and has been changed each year based on student feedback. During an informal exercise on the last day, students are asked to provide feedback on what they would change and would not change in the course. For instance, in the first year, the pharmacy students said they felt that teaching specific to pharmacy had been greatly lacking. As a result, modules of specific pharmacy content were built in the subsequent years, and the continuous presence of profession-specific material was ensured throughout. The faculty has become increasingly aware over the years of the importance of discipline-specific teaching within the course. This is confirmed by Koffman (23), who states that such sessions "can be helpful to reaffirm participants' roles and professional identities." All forms of feedback are reviewed by the core faculty each year in deciding the following year's content.

\section{LESSONS LEARNED}

There have been many lessons learned in the four years that the course has been offered. As a result, changes have been made to both the content of the curriculum and the process of course delivery. The original course design took students through what was conceptualized as the "life process" of palliative care: from general information about palliative care and its history through medical and psychosocial issues of various diseases to death and bereavement. However, this design, in conjunction with the concentrated nature of the course being delivered in an intensive format over one month, served to exhaust the students. As a result, the curriculum was redesigned such that the process or feeling-oriented emotional work was situated in the middle of the four weeks and, therefore, was led into and followed by theoretical teachings. Subsequently, the teaching methods were primarily didactic at the beginning and end, and experiential in the middle.
Time for debriefing after clinical days was built into the timing of the course in the first year. In subsequent years, this was eliminated because the faculty found that when the students needed to talk about an intense or touching experience, they did so in the context of the regular classroom discussions. Therefore, a margin of flexibility was permitted within the teachings to allow for it when it arose spontaneously. Students are always encouraged to talk in the class about their reactions to the material and to reflect on their learning.

There have been ongoing issues about the recruitment of students. The participation of medical students has ranged from one in one year to the full complement of four students. Scheduling an intensive four-week course within an already consuming program of study has proven to be difficult. Similarly, there have been recruitment issues with nursing students, most of whom are working and need to take the course while on holidays. Some years, this has meant fewer than four nursing students. Social work and pharmacy students have been consistently available and interested over the years. As a result, there have been some years with up to six students from pharmacy and social work, who were recruited to fill in the gaps left by medicine and nursing.

An additional challenge has been the varied expectations in the professions involved in this course. For example, the medical students are graded only on a pass/fail basis and, in the initial years, it was unclear as to whether the course would appear on their academic record. This resulted in tensions on the student teams between those with differing expectations of work levels. However, this has not been consistently an issue and has effectively disappeared since the clarification that the course does appear on every student's academic record.

The course has evolved to include a spectrum of palliative care across the lifespan. In the initial planning of the course, an effort was made to include pediatric palliative care as both distinct from and similar to adult care. In the first year, before the inclusion of Canuck Place as an extended clinical site, the pediatric content was limited to one three-hour presentation and a tour of the children's hospice. Since then, pediatric content has become more infused throughout the four-week curriculum. This is due in part to the inclusion of the pediatric clinical site. Secondly, one of the core faculty members works in both adult and pediatric palliative care, and brings that perspective to the classroom on a daily basis. In addition, sessions 
are more inclusive of various professionals who work in pediatric care. For instance, the spiritual care provider from the children's hospice was invited to join in the teaching of the module on teamwork. All of this has helped bring pediatric palliative care into the mainstream knowledge of the students, while still acknowledging how it is different from adult care.

\section{FUTURE DIRECTIONS}

At present, the four professions involved in the course are medicine, nursing, pharmacy, and social work. Instructors from various other disciplines, such as physical therapy and spiritual care, are included in the teaching of the various modules of the classroom delivery. Much thought has been given to expanding the number of professions involved in the course and inclusion of students from other professions is a long-term goal. Barriers to this are various. For instance, schools of theology, from which spiritual care students might be drawn, are not part of the College of Health Disciplines, which oversees the course. The faculty members believe it is very important to have professional mentorship, both in the classroom and in the clinical placements. It is not enough to integrate additional students if they are not going to have a faculty mentor in the classroom and at the various clinical sites. The burden of larger student teams has also been a factor in the current situation. For clinical sites to have more students in their midst requires a stronger commitment. At present these relationships are building and the faculty is not yet ready to request more from the clinical sites.

The faculty members are aware of an ongoing need to plan for future faculty members. So far, one faculty member has retired and the planning for another to stop teaching the course is in the works. The time for faculty members to teach the course has been somewhat of an issue over the years. Faculty members have varying amounts of support from their institutions and colleagues; only one is currently a full time academic with dedicated teaching time. Some take holidays in order to teach in the course and others are able to juggle their schedules. Student feedback concerning the richness of being taught by professionals who are actually working in the field indicates it is worth the effort.

Ultimately, the effectiveness of this course is demonstrated in the awareness of the issues of death and dying, and of whole-person care that the students bring to their professional practice lives, whether they work in palliative care or elsewhere. While the authors hope to under- take research in the future to follow up with the students who have taken the course over the years, and to determine whether and how they have incorporated learning about palliative care into their professional lives, the feedback to date has indicated that a great deal of education has occurred. Reflections from the professionals supporting the educational process at clinical sites as well as in the classroom confirm that the students are engaging in an effective learning process, as evidenced by the posing of appropriate questions and meaningful dialogue.

The collaborative process between educators and clinical sites has resulted in strengthening existing relationships within the palliative care community. As such, gathering the resources of the palliative care community to work toward a shared educational goal has been another achievement of the course. As both palliative care and interprofessional practice become a central component of health care, this course provides both a source of information for the practice of palliative care and a model of interprofessional teamwork.

Date received, January 9, 2007; date accepted, April 24, 2007.

\section{ACKNOWLEDGEMENTS}

The authors would like to acknowledge the contribution of Bertie Glusman and Leah May Walker in the Division of Palliative Care at UBC, as well as all the faculty members who have taught in the course over the years. We could not have done it without you; thank you.

\section{REFERENCES}

1. Reese DJ, Sontag MA. Successful interprofessional collaboration on the hospice team. Health Soc Work 2001; 26: 167-175.

2. Rock W. Interdisciplinary teamwork in palliative care and hospice settings. Am J Hosp Palliat Care 2003; 20: 331-333.

3. Wee B, Hillier R, Coles C, Mountford B, Sheldon F, Turner P. Palliative care: a suitable setting for undergraduate interprofessional education. Palliat Med 2001; 15: 487-492.

4. Doyle D, Hanks G, Cherny Ni, Calman K (eds). Oxford Textbook of Palliative Medicine. $3^{\text {rd }}$ edition. New York: Oxford University Press, 2004.

5. Fineberg IC, Wenger NS, Forrow L. Interdisciplinary education: evaluation of a palliative care training intervention for pre-professionals. Acad Med 2004; 79: 769-776.

6. Cohen LM. Palliative care for patients who have discontinued dialysis. Home Health Care Consultant 2002; 9: 26-30.

7. Health Canada. Pan-Canadian Health Human Resource Strategy. [Online]. Cited 2006 Dec 7. Available from http://hc-sc.gc.ca/hcs-sss/pubs/care-soins/2006wait-attente/hhr-rhs/index_e.html

8. Sellick SM, Charles K, Dagsvik J, Kelley ML. Palliative care providers' perspectives on service and education needs. J Palliat Care 1996; 12(2): 34-38. 
9. Howe J, Sherman D. Interdisciplinary educational approaches to promote team-based geriatrics and palliative care. Gerentol Geriatr Educ 2006; 26: 1-16.

10. Fillion L, Fortier M, Goupil RL. Educational needs of palliative care nurses in Quebec. J Palliat Care 2005; 21(1): 12-18.

11. Latimer EJ, Kiehl K, Lennox S, Studd S. An interdisciplinary palliative care course for practising health professionals: ten years' experience. J Palliat Care 2001; 14(4): $27-33$.

12. Fulmer T, Flaherty E, Hyer K. The Geriatric Interdisciplinary Team Training (GITT) Program. Gerontol Geriatr Educ 2003; 24(2): 3-12.

13. Turner $P$, Sheldon F, Coles C, Mountford B, Hillier $R$, Radway $P$, Wee, $B$. Listening to and learning from the family carer's story: An innovative approach in interprofessional education. J Interprof Care 2000; 14: 387-395.

14. Serwint JR, Rutherford LE, Hutton N, Rowe PC, Barker S, Adamo G. I learned that no death is routine: Evaluation of a death and bereavement seminar for pediatric residents. Acad Med 2002; 77: 278-284.

15. Macleod RD, Parkin C, Pullon S, Robertson G. Early clinical exposure to people who are dying: learning to care at the end of life. Med Educ 2003; 37: 51-58.

16. Johnston M, Stephanson E, Nicholson K. Psychosocial pediatric palliative care. In: Downing $M$ (ed).
Medical Care of the Dying. $2^{\text {nd }}$ edition. Victoria, British Columbia: Victoria Hospice Society, 2006.

17. Pirrie A, Hamilton S, Wilson V. Multidisciplinary education: Some issues and concerns. J Educ Res 1999; 41(3): $301-314$

18. Gilbert JHV. Innovation to practice: Getting the "inter" into professional. In: EdHealth Conference, College of Health Sciences. Sydney, Australia; 2005.

19. O'Neill B, Wyness MA. Student voices on an interprofessional course. Med Teach 2005; 27(5): 433-438.

20. Wyness MA, O'Neill B, McKinnon S, Granger P, Goldstone I, Martel R, Chalmers A, Perchal P. Interprofessional education: One aspect of achieving quality health and social care. In: Rushmer RK, Davies HTO, Tavakoli M, Malek M (eds). Organisational Development in Health Care: strategic issues in health care management. Aldershot, England: Ashgate; 2002, pp. 60-73.

21. Manthorpe J. Developing carers' contributions to social work training. J Soc Work Educ 2000; 19(1): 19-27.

22. Cloonan PA, Davis FD, Burnett CB. Interdisciplinary education in clinical ethics: a work in progress. Holist Nurs Pract 1999; 13(2): 12-19.

23. Koffman J. Multiprofessional palliative care education: past challenges, future issues. J Palliat Med 2001; 17: 86-92.

\section{Appendix 1}

\section{Course Objectives}

\section{Interprofessional Objectives}

The student will:

1. Value the unique professional contributions, differing professional perspectives, and interprofessional teamwork in the provision of quality care.

2. Understand the roles, regulatory frameworks, responsibilities and professional capabilities of members of other professions.

3. Understand concepts basic to effective teamwork including self-awareness and cultural diversity.

4. Apply concepts of confidentiality and professional boundaries to interprofessional work.

5. Understand the influence of personal and professional values and beliefs on interprofessional teamwork and practice.

6. Demonstrate the ability to establish and maintain relationships within an interprofessional team.

7. Demonstrate an understanding of practice environments and their influence on team collaboration and provision of care.

\section{Palliative-Care-Specific Objectives}

\section{The student will:}

1. Understand that interventions should be centred on the patient's needs, desires, and beliefs in order to support patient's control of decisions that affect care.

2. Practise with the unit of care as the family, through consideration of the family's background and the impact of the illness upon the family group, in particular, the family caregivers.

3. Identify their own beliefs and attitudes towards death and dying, and identify and respect patient and family beliefs and attitudes towards death and dying.

4. Recognize that care involves more than diagnosing and treating a disease and that illness/dying are complex states with physical, emotional, psychosocial, and spiritual elements.

5. Demonstrate communication skills with patients and families, as well as explain how and why these techniques should be modified to reflect the personal, educational, social, and cultural background of the patient and family.

6. Understand common symptoms, including total pain, and approach symptom assessment and management in a holistic manner.

7. Anticipate the illness trajectory of common life-threatening illnesses and recognize the opportunities for advanced care planning within this trajectory.

8. Recognize the nature of life-limiting illnesses unique to children and the types of programs needed to support them and their families.

9. Describe the physiological and psychospiritual changes associated with imminent death, and identify comfort measures for patients and their families.

10. Engage in discussions on ethical and legal aspects of caregiving, and explore strategies for resolving these issues.

11. Identify collaborative partnerships and various organizational arrangements for the seamless delivery of palliative care and the relationship of these organizational structures within the existing health care system.

12. Describe the elements of grief reactions and interventions to promote and facilitate healthy grieving through supporting the patient and family during the illness and beyond. 